children. especially babies, the patients are much affected by loss of blood and if this bloodletting is performed it seems to me that a suline infusion should always be used to take its flace. I am of the opinion that it would be very important to have a standard whereby we could know just how much blood to let in certain cases according to the age and condition of the child. I should say that it would be indicated only if the child was robust and strong and contra-indicated in case, of anemia and malnutrition.

Dr. Abranda JAConI, New York: I can only repent what I said forty yeurs ago (New York Med. Record of 1870), and forty years ago I spoke on un experience of seventeen years in practice in New York. I have not molified my opinion expressed at that time. We must not forget that we cunnot say beforehand uniformly just liow much blood should be taken. The patients and the cases are not alike. We should remember that the amount of blood is present in a different percentage in the adult. The baly has about 5 per cent. of its weight in blood ( 1 part blood in $191 / 2$ body weight) while the adult has nearly 8 per cent. ( 1 part blood in 13 body weight). If a child weighs 40 pounds, about 2 pounds only would be the amount of blood in that child and in that proportion only the blood should be taken. No large percentage of the amount circulating in the body should be taken away.

Dr. Heishich Sterx, New York: Dr. Jacobi has again hit the nail on its head. The umount of blood to be abstracted in the young should always be in proportion to the amount contrined in the organism, and we know that the blood ratio in ehildren is decidedly smaller than in the adult. It should never exceed, in the general run of chses 50 to 100 e.c.

AN ORIGINAT METHOD FOR PREVENTION OF PERFORATION IN S SUBMUCOUS RESECTION

RICHARD M. NELSON, M.D.

Eye, Enr. Nose and Throat cinle, Colon Hospltal Cristobal, Canat yone

In every adverse criticism of the operation of submucons resection for the correction of deviation or deflec-. tion of the nasal septum which I have read or have heard, the grentest stress has always been laid on the danger of perforation resulting therefrom. Indeed, such great Posterior nares emphasis is laid on this danger,

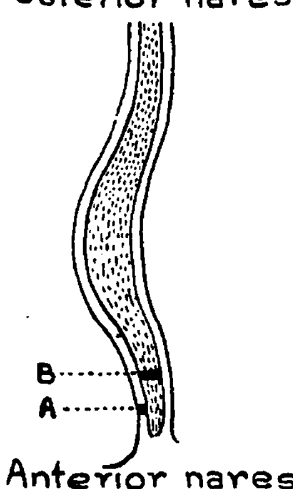

Wiagrammatic horjontit section through a septim deflected to the right. A, Initind inclsion through mucous mem-
brane down to cartilage. blane down to cartilage.
(Tisual metlood is to eut through curtlinge also hare.) B, I $n$ e is i i n through rartlluge only. a guarter or an eighth of an fuch poutertor to Incin inch posterior to bision in mucous mem. biane. Both incisions, from the right. that in every such operation which I lave performed the dread of this occurrence has ever been foremost in my mind.

Believing that it ought to be possible to devise some modification of the usual steps of this operation rendering the danger of perforation less than was to be apprehended with existing methods, I set to work to put into practical use an idea that had often suggested itself to me in operating after the usual method. I noted on several occasions that in dissecting or separating the mucous membrane from the cartilage on both sides, although I several times made "buttonholes" in the mucous mernbranes of both sides in a single operation, I never had a perforation result.

In looking for an explanation for this I noted that in no case had any two "buttonholes" been made opposite one another. The idea naturally suggested itself to apply this principle in making the initial incisions. In the next operation, after making the first incision through the mucous membrane, etc., down to the cartilage, and separating the membrane from it as far back as necessary, instead of cutting through the cartilage at the same line of incision followed in going through the membrane, the cartilage was carefully cut through from one-eighth to one-fourth inch posterior to the incision through the mucous membrane. The rest of the operation was done alter the usual metliods. At the cloge of the operation, instead of the cartilage being cut off flush with the incision through the mucous membrane, there was left a projecting ledge of cartilage extending from oneeighth to one-quarter of an inch posteriorly from the line of this incision. In bringing the raw surfaces of mucous membrane together this projecting ledge of cartilage was found not only to be completely covered over, but also to appear to aid very materially in holding the elges of the wound in close apposition, acting somewliat as a natural splint.

I have tried this method in a series of cases with uniform results, without a perforation, and I would state that in my opinion with ordinary care and rensonable exercise of even moderate skill it is practically impossible to produce a perforation in using this method of making the primary incisions.

\section{A PRACTICAL MECHANICAL METHOD OF END-TO-END ANASTOMOSIS OF BLOOD-VESSELS}

\section{USING AIBSORBABLE MAGNESIUM RINGS}

V. D. LESPINASSE. M.D., G. CARI FISHER, M.D., AND J. EISENSTAEDT, M.D., D.D.S.

CHicago

This work was done in the laboratory of the department of Experimental Surgery of Northwestern University Medical School, with the cooperation and assistance of Prof. Robert Zeit and Drs. Wolfer, Violet Deason and Solmon. It is accomplished by the use of rings of metallic magnesium.

\section{PIIYSICAL PROPERTIES AND METALLURGY OF MAGNESIUM}

Magnesium is a hard, silver-white metal, having a specific gravity of 1.75 and possessing a melting point of $\$ 00$ degrees. As it tarnishes in the air the bright Iuster is soon lost, but the change is unimportant at the ordinary temperature. At a high temperature combustion follows, with production of the well-known brilliant white light. At ordinary room temperature the action increases and hydrogen gas is slowly liberated, the hydroxid of magnesium being formed at the same time.

The action of water on magnesium is hastened by the presence of salts, such as sodium chlorid, from whicli it jolluws that in the juices of the body the solution or disappearance of the metal would be more rapid than in water alone. However, even with salts present, the action is relatively slow and the hydrogen set free is searcely appreciable. Under proper conditions $24 \mathrm{milli}$ grams of magnesium will liberate 2 milligrams of hydrogen, or 22.4 c.c. at the normal temperature of zero centigrade. 'This volume would be somewhat greater at body temperature; approximately, $1 \mathrm{mg}$. of the metal will liberate 1 cubic centimeter of the gas. 